\title{
Influence of fixed-dose combination perindopril/ amlodipine on target organ damage in patients with arterial hypertension with and without ischemic heart disease (results of EPHES trial)
}

This article was published in the following Dove Press journal:

Vascular Health and Risk Management

\section{Ganna D Radchenko Liliya O Mushtenko Yuriy M Sirenko}

State Institute "National Scientific Center "Institute of Cardiology named after acad.M.Strazhesko" of Ukrainian National Academy of Medical Science, Kyiv, Ukraine
Correspondence: Ganna D Radchenko State Institute National Scientific Center, "Institute of Cardiology Named After Acad.M.Strazhesko" of Ukrainian National Academy of Medical Science, 5, Narodnogo Opolchenia Str., Kyiv 03680, Ukraine

Tel +380667128405

Fax +380 44249704 I

Email rganna@bigmir.net
Background: The EPHES trial (Evaluation of influence of fixed dose combination Perindopril/amlodipine on target organ damage in patients with arterial HypErtension with or without iSchemic heart disease) compared the dynamics of target organ damage (TOD) in hypertensive patients with and without ischemic heart disease (IHD) treated with the fixed-dose combination (FDC) perindopril + amlodipine.

Methods: The analysis included 60 hypertensive patients (aged $>30$ years): 30 without IHD and 30 with IHD. At randomization, FDC was administered at a daily baseline dose of 5/5 mg with uptitration to $10 / 10 \mathrm{mg}$ every two weeks. If target blood pressure $(\mathrm{BP}<140 / 90 \mathrm{mmHg})$ was not achieved after six weeks, indapamide $1.5 \mathrm{mg}$ was added to the regimen. All patients underwent body mass index measurements, office and ambulatory BP measurements, pulse wave velocity (PWVe) and central systolic BP evaluation, augmentation index adjusted to heart rate 75 (Aix@75) evaluation, biochemical analysis, ECG, echocardiography with Doppler, ankle-brachial index measurement, and intima-media thickness measurement. The follow-up period was 12 months. Results: Therapy based on FDC perindopril/amlodipine was effective in lowering BP (office, ambulatory, central) in both groups. We noted significant decrease in Aix@75 with the therapy in both groups, but $\Delta \mathrm{Aix} @ 75$ was lesser in the group with IHD than the group without IHD. FDC provided significant improvement in PWVe and left ventricular diastolic function, and decrease in albuminuria, left ventricular hypertrophy $(\mathrm{LVH})$, and left atrium size. $\triangle \mathrm{PWVe}$ was significantly $(P<0.005)$ less in patients without IHD than those with IHD $(2.5 \pm 0.2$ vs $4.4 \pm 0.5$ $\mathrm{m} / \mathrm{s}$, respectively). In spite of almost equal $\mathrm{LVH}$ regression, the positive dynamics of $\Delta \mathrm{E} / \mathrm{A}$ and $\Delta \mathrm{E} / \mathrm{E}^{\prime}$ were more in patients with IHD than those without IHD (64.4\% and $54.1 \%$ vs 39.8 and $23.2 \%$, respectively; $P<0.05$ for both comparisons). Adverse reactions were in $2(6.5 \%)$ patients without IHD and $3(10 \%)$ with IHD $(P=\mathrm{NS})$. In the group with IHD, we noted significant decrease in angina episode rate - from $2.5 \pm 0.4$ to $1.2 \pm 0.2(P<0.01)$ per week.

Conclusion: Thus, treatment based on FDC was effective in decreasing BP and TOD regression in both patients with and without IHD. However, the dynamics of changes in TOD were different between the two groups, which should be taken into consideration during management of patients with and without IHD.

Keywords: arterial hypertension, ischemic heart disease, target organ damage regression, fixed-dose combination, prospective observation, perindopril, amlodipine

\section{Introduction}

Target organ damage (TOD) is the result of persistent high blood pressure (BP). It is a factor influencing the prognosis and a marker for evaluation of antihypertensive 
effectiveness. It is known that TOD and its regression depends on the BP level. In some studies, correlations were noted between BP reduction and regression of left ventricular hypertrophy (LVH), ${ }^{1-3}$ albuminuria, ${ }^{4,5}$ and arterial stiffness. ${ }^{6}$ The regression of TOD is associated with better prognosis. In the LIFE trial, a decrease in left ventricular mass index (LVMI) by $25 \mathrm{~g} / \mathrm{m}^{2}$ was associated with a decrease in the combined end point, cardiovascular death, myocardial infarction, stroke and death from any cause by $22 \%, 38 \%$, $15 \%, 24 \%$, and $28 \%$, respectively. Patients with high level of proteinuria at baseline and at one year of treatment had higher risk of cardiovascular complications than patients with low one-year on-treatment proteinuria level. ${ }^{7,8}$ In the ADVANCE trial, the fixed-dose combination (FDC) perindopril/indapamide decreased the level of albuminuria and risk of all-cause death by $14 \%$ in patients with diabetes mellitus. ${ }^{9}$ In patients with renal failure, the lowering of aorta pulse wave velocity (PWVe) by $1 \mathrm{~m} / \mathrm{s}$ led to decrease in all-cause death risk by $29 \% .^{10}$

It is believed that all BP-lowering drugs are effective in TOD regression, but the degree of this regression may vary based on the choice of therapy. Some trials demonstrated that TOD regression was associated with improved prognosis, but not with all therapy. In the ROADMAP trial, olmesartan prevented albuminuria, but not the end point development. ${ }^{11}$ In the ELSA trial, lacidipine prevented increase in carotid intima-media thickness (IMT) better than atenolol, but was not associated with decreased rate of complications. ${ }^{28}$ Thus, the search for optimal antihypertensive therapy that can prevent the occurrence and progression of TOD, thereby improving the overall prognosis, is the need of the hour in medical practice.

Ischemic heart disease (IHD) is a multifactorial disease, and high BP is a main risk factor for its development. ${ }^{12}$ The INTERHEART study demonstrated that dyslipidemia and hypertension increased the risk of myocardial infarction by $50 \%$ and $25 \%$, respectively. ${ }^{13}$ High BP was shown to accelerate the atherosclerotic process and lead to TOD, which in turn aggravated the IHD course. Also hypertension could be connected with IHD though the other cardiovascular risk factors - and dyslipidemia, and high BP are associated with obesity. ${ }^{14}$ It is unknown whether there are any differences in TOD and their regression between hypertensive patients with and without IHD.

The EPHES study (Evaluation of influence of fixed dose combination Perindopril/amlodipine on target organ damage in patients with arterial HypErtension with or without iSchemic heart disease) aimed to compare the TOD at baseline and evaluate the effects of FDC perindopril/ amlodipine on TOD regression in hypertensive patients with and without IHD. The choice of this FDC was made because of a few reasons. First, we wanted to compare the regression of TOD in the presence of IHD. To achieve this, our patients needed to take identical antihypertensive therapy. Second, the ALLHAT, EUROPA, and ASCOT trials showed the high effectiveness of amlodipine, perindopril, and their combination in patients with hypertension and IHD. Thus, FDC perindopril/amlodipine has indications for both hypertension and IHD.

\section{Materials and methods}

\section{Patients}

A total of 65 patients with essential hypertension aged $>30$ years were included in the study. Five patients were excluded before 6 months of treatment: 2 because of adverse reactions and 3 due to their personal reasons. Thus, 60 patients finished the 12-month therapy. In patients without therapy, the level of systolic BP (SBP)/diastolic BP (DBP) had to be $>160 / 100$ $\mathrm{mmHg}$, but $<200 / 120 \mathrm{mmHg}$, whereas in patients on therapy, the levels had to be $>140 / 90 \mathrm{mmHg}$, but $<200 / 120 \mathrm{mmHg}$. Each patient signed the informed consent form. The protocol was approved by the local ethic committee of State Institution "National Scientific Center 'Strazhesko's Institute of Cardiology" of National Academy of Medical Science of Ukraine.

On the basis of signs of IHD, the patients were randomized into two groups. The first group included 30 patients without signs of IHD, and the second group included 30 patients with signs of IHD.

The exclusion criteria were: SBP and/or DBP > 200 and/ or $120 \mathrm{mmHg}$, secondary or resistant hypertension, history of myocardial infarction or stroke, valvular heart diseases, uncontrolled arrhythmia, heart failure of New York Heart Association (NYHA) functional class III-IV or ejection fraction $<50 \%$, chronic obstructive lung diseases, uncontrolled diabetes mellitus, renal diseases with glomerular filtration rate $(\mathrm{GFR})<45 \mathrm{~mL} / \mathrm{min} / 1.73 \mathrm{~m}^{2}$, hepatic failure or increased level of hepatic enzymes more than 3 times the upper limits of normal, secondary hypertension, bilateral significant stenosis of renal arteries or significant stenosis of single renal artery, oncology diseases, psychological disorders, history of intolerance or adverse events on amlodipine or angiotensinconverting enzyme inhibitor (ACEi) therapy, history of angioneurotic edema, refusing to sign the informed consent form, and participation in other trial. Patients younger than 30 years were excluded because we needed baseline comparable groups, but IHD is a rare disease in this age group. 
Criteria for IHD included clinical typical angina and electrocardiographic (ECG) changes during exercise tests and/or signs of coronary atherosclerosis during coronary angiography (traditional or computer tomography $[\mathrm{CT}]$ angiography). Ten patients $(30 \%)$ with IHD had a history of coronary stenting (one or two stents). We excluded patients with a history of myocardial infarction or who needed stenting within the next 12 months (coronary artery stenosis $>70 \%$ ).

Patients could be withdrawn from the study in case of withdrawal of consent, nonachievement of target BP level $(<140 / 90 \mathrm{mmHg}$ ) during 6 months of treatment, adverse reactions requiring therapy discontinuation, or worsening of the patient's clinical state that was not connected with the study therapy, but led to additional examinations or administration of concomitant drugs not permitted by the study protocol.

\section{Treatment}

On the day of randomization, all patients were administered FDC perindopril/amlodipine (Bi-Prestarium; Servier, Suresnes, France) at a starting dose of $5 / 5 \mathrm{mg}$ OD. In case of nonachievement of the target BP level, the dose could be increased with 2-week uptitration to $10 / 10 \mathrm{mg}$. If the target BP level was not achieved after 6 weeks, the indapamide-SR $1.5 \mathrm{mg}$ (Arifon-retard; Servier) could be added for 4 weeks. Beta-blockers and alfa-blockers could be added as needed for better BP control in both groups. In the group with IHD, beta-blockers and short-acting nitrates were permitted. The patients were not supported for antihypertensive drugs and bought the medications by themselves.

If a patient could not achieve the target BP level $(<140 / 90 \mathrm{mmHg})$ within 6-month therapy, he or she was excluded from the study for further examination of the resistance reasons. That patient could be replaced by another patient who matched the inclusion criteria.

All patients with IHD and some without IHD but at high cardiovascular risk took statins (atorvastatin at a mean dose of 22.0 $\pm 1.6 \mathrm{mg}$ daily or rosuvastatin at mean dose of $12.5 \pm 0.95 \mathrm{mg}$ daily) ${ }^{12,15}$ and acetylsalicylic acid (ASA) in preventive doses (75-100 mg daily). It was permitted to use unsaturated fatty acids and short-acting nitrates on demands. If a patient needed to take nitrates constantly, he or she was excluded from the study.

\section{Methods}

All patients underwent body mass index (BMI) measurement, office SBP and DBP measurements, 24-hour ambulatory BP monitoring (ABPM), PWVe measurement on aorta and arteria radialis $(\mathrm{PWVm})$, aorta $\mathrm{BP}$ evaluation, echocardiography (EchoCG), ECG, carotid IMT evaluation, ankle-brachial index measurement, and biochemical blood analysis. The protocol is presented in Table 1. Follow-up period was 12 month.

Office SBP and DBP were measured automatically by OMRON-705IT (OMRON 705IT device; Omron Healthcare

Table I Study protocol

\begin{tabular}{|c|c|c|c|c|c|c|c|c|}
\hline Evaluation/visits & Visit I & Visit 2 & Visit 3 & Visit 4 & Visit 5 & Visit 6 & Visit 7 & Visit 8 \\
\hline Periods & $-2-0$ day & I day & 2 weeks & 4 weeks & 6 weeks & 10 weeks & 6 months & 12 months \\
\hline Anamnesis & + & & & & & & & \\
\hline Questioner test & + & & & & & & & + \\
\hline BMI & & + & & & & & & + \\
\hline Office SBP, DBP, HR & + & + & + & + & + & + & + & + \\
\hline ECG & + & & & & & & & + \\
\hline 24-hour ABPM & & + & & & & & & + \\
\hline Doppler EchoCG & & + & & & & & & + \\
\hline Pulse wave analysis (PWVa, & & + & & & & & & + \\
\hline \multicolumn{9}{|l|}{ PWVm, Aix @75, aorta SBP) } \\
\hline Hematology & + & & & & & & & \\
\hline Biochemical analysis with GFR & & + & & & & & & + \\
\hline \multicolumn{9}{|l|}{ calculation } \\
\hline Albuminuria & & + & & & & & & + \\
\hline Carotid IMT & & + & & & & & & + \\
\hline Measurement $\mathrm{ABI}$ & & + & & & & & & + \\
\hline Antihypertensive drug treatment & & + & + & + & + & + & + & + \\
\hline Adverse events & + & + & + & + & + & + & + & + \\
\hline
\end{tabular}

Abbreviations: ABI, ankle brachial index; ABPM, ambulatory blood pressure monitoring; Aix@75, augmentation index adjusted to HR 75 beats per minute; BMI, body mass index; DBP, diastolic blood pressure; EchoCG, echocardiography; ECG, electrocardiography; GFR, glomerular filtration rate; HR, heart rate; IMT, intima-media thickness; $\mathrm{PWVa}$, aorta pulse wave velocity; PWVm, muscular pulse wave velocity; SBP, systolic blood pressure. 
Co., Ltd., Kyoto, Japan) three times. The average of three sequenced measurements was taken into consideration. HR was evaluated at the second measurement.

For BMI calculation the standard formula was used: BMI $=$ weight $/(\text { height })^{2}\left(\mathrm{~kg} / \mathrm{m}^{2}\right)$.

ECG was done at baseline and at the end of treatment period using device Unicard (Unicard, Kyiv, Ukraine). We evaluated the signs of arrhythmias and LVH: Sokolow index (SV1+RV5/RV6 $>35 \mathrm{~mm}$ ), voltage Cornel index (R aVL+S V3 $>28 \mathrm{~mm}$ for men and $>20 \mathrm{~mm}$ for female), and duration Cornel index ( $>2400 \mathrm{~mm} \times \mathrm{ms}$ ).

For ABPM we used a portable ABPM-04 device (Meditech, Budapest, Hungary). ABPM report included average SBP and DBP (24-hour SBP and 24-hour DBP) and HR, daytime and nighttime SBP and DBP, variability (SD) of daytime and nighttime SBP and DBP, percentage of SBP decrease at night compared to daytime, daily index (DI), and morning surge. Morning surge was defined by differences between maximal SBP at period 6:00-12:00 and minimal SBP at nighttime ${ }^{16}$ The standard protocol included measurements every 15 minutes during the day and every 30 minutes during the night (from 10:00 pm to 6:00 am). In case of unsuccessful ABPM, we provided repeated 24-hour monitoring and excluded patients who failed the second ABPM. Successful ABPM included number of readings not $<70 \%$ of expected measurements. Patients were suggested daily activities normal for them without overworking or psychoemotional stress.

In certified laboratory of State Institute "National Scientific Center 'Institute of Cardiology named after academician M D Strazhesko' of National Academy of Medical Science" of Ukraine, the biochemical analyses were provided by automatic photometer (Cormay Livia Chemistry Analyzer; PZ Cormay S.A, Lublin, Poland). CKD-EPI formula was used for GFR calculation. ${ }^{17}$

Albuminuria was measured by analyzer Clinitek Advantus (Siemens Healthcare GmbH, Erlangen, Germany) in 24-hour urine.

Sphygmocor-PVx device (AtCor Medical Pty Ltd., Sydney, Australia) was used for assessment of PWVe, PWVm, aorta SBP, central pulse pressure, and Aix@75. The probes were stated on the common right carotid, femoral, and radial arteries under visual automatic quality controls. The distance between the probes was measured by centimeter ribbon. The elastic artery stiffness (PWVe) was evaluated on the carotid artery-femoral artery segment, and the muscular artery stiffness (PWVm) was evaluated on the carotid artery-radial artery segment. After entering the brachial SBP and DBP data, the central SBP, central pulse BP, and
Aix@75 were calculated automatically. In the device, the normal level of central SBP was calculated automatically after age adjustment.

We used Sonos 5500 (Hewlett Packard, Palo Alto, CA, USA) for IMT measurements. According to the American Society of Echocardiography 2008 guidelines, the average of three IMT measurements in the right and left carotid arteries was considered. ${ }^{18}$ The maximal IMT (IMTmax) was also calculated.

Three consecutive measurements were performed to determine the mean value of ankle-brachial index by the automatic device Omron M-10 (Omron Healthcare Co., Ltd.).

EchoCG was done for all patients using Sonos 5500 according to the extended protocol recommended by the European Association of Cardiovascular Imaging. The following were measured: volumes of the heart chambers, dimensions of the major vessels, ejection fraction, and left ventricular diastolic function (peak early mitral inflow velocity $[\mathrm{E}]$, the peak velocity during atrial contraction [A], E/A ratio, peak early diastolic mitral annular velocity [E'], and $\mathrm{E} / \mathrm{E}^{\prime}$ ratio). LVMI was calculated using the formula given by the American Society of Echocardiography. ${ }^{12,19,20}$

For confirmation of IHD we conducted treadmill exercise test using Cardio PC device (Innomed Medical, Budapest, Hungary). Coronary angiography was provided by direct catheterization or high-resolution CT.

Each investigation was conducted by separate independent specialist who did not participate in the study directly and was not interested in the study results. The same specialists and the same devices were used for each investigation in a particular patient.

\section{End points of the study}

The primary end points were lowering of BP (office, ambulatory, central), significant dynamics of TOD, and therapy tolerance. The secondary end points were target BP level achieving rate; dynamics of ABPM additional patterns (variability, DI, morning surge), central SBP normalization, and biochemical changes.

\section{Statistics}

The data are expressed as the mean $\pm \mathrm{SE}$ or as a percentage. All statistical calculations were performed using the Statistical Package for Social Sciences version 16.0 (SPSS Inc, Chicago, IL, USA). The statistical significance of between-group differences was estimated using the independent $t$-test of mean values, the Mann-Whitney $U$ test (in the case of non-normal distribution) for continuous variables, and chi-squared analy- 
sis for categorical variables. Comparisons of changes on treatment were made using the paired two-sample $t$-test for means. Statistical significance was assumed at $P<0.05$.

\section{Results}

\section{Baseline clinic-demographic differences between groups}

The clinical characteristics of patients are presented in Table 2. The groups were adjusted for age, duration of arterial hypertension, baseline office SBP and DBP levels, BMI, history of heart failure, and albuminuria rate. However, the group with IHD had more number of males (76.7 vs $46.7 \%$, $P<0.02$ ), more patients with diabetes mellitus (26.7 vs $6.7 \%$, $P<0.05)$, and more patients with history of atrial fibrillation (20 vs $3.3 \%, P<0.05$ ) than the group without IHD. Baseline on-therapy rate was much higher in the IHD patients $(90 \%$ were on combination). Beta-blockers were used more often, but calcium channel blockers (CCBs) less commonly, in the group with IHD. Hence, the patients with IHD had significantly less baseline HR $(68.4 \pm 2.1$ vs $78.1 \pm 2.8, P<0.01)$. All patients with IHD took statins and ASA, while only $63.3 \%$ and $46.7 \%$ respectively $(P<0.001$ and $P<0.001)$ of the patients without IHD took these medicines.

\section{BP level dynamics}

Office SBP, DBP, and HR are presented in Figure 1. At baseline, at 6 month, and at the end of study, the groups did not differ significantly in terms of SBP and DBP levels. However, on 1-3 months of treatment, patients with IHD had less SBP and DBP levels than patients without IHD. In both groups, all patients achieved target BP level $(<140 / 90$ $\mathrm{mmHg})$. Indapamide-SR was added significantly $(P<0.005)$ more frequently in patients without IHD - $18(60 \%)$ vs 7 (23.3\%), $P<0.05$ - but beta-blockers, conversely, to patients with IHD $-29(96.7 \%)$ vs $1(3.3 \%), P<0.001$. HR was less in patients with IHD at all periods of treatment.

Table 2 Baseline characteristics of patient groups (mean \pm SE, $n(\%)$ )

\begin{tabular}{|c|c|c|}
\hline Characteristics & $\begin{array}{l}\text { First group } \\
\text { without IHD, } n=30\end{array}$ & $\begin{array}{l}\text { Second group } \\
\text { with IHD, } n=30\end{array}$ \\
\hline Mean age, years & $46.2 \pm 5.4$ & $56.2 \pm 4.8$ \\
\hline Hypertension duration, years & $6.8 \pm 3.2$ & $7.8 \pm 3.2$ \\
\hline Screening office SBP, $\mathrm{mmHg}$ & $156.4 \pm 3.8$ & $148.4 \pm 2.8$ \\
\hline Screening office DBP, $\mathrm{mmHg}$ & $96.3 \pm 2.2$ & $91.1 \pm 2.2$ \\
\hline Screening office $H R$, beats per minute & $78.1 \pm 2.8$ & $68.4 \pm 2.1 * *$ \\
\hline $\mathrm{BMI}, \mathrm{kg} / \mathrm{m}^{2}$ & $34.2 \pm 2.1$ & $32.1 \pm 2.5$ \\
\hline Male/female, n (\%) & $14(46.7) / 16(53.3)$ & $23(76.7) / 7(23.3)^{* *}$ \\
\hline History of angina, $\mathrm{n}(\%)$ & & $24(80)$ \\
\hline Positive exercise test, $\mathrm{n}(\%)$ & & $18(60)$ \\
\hline Coronary angiography without stenting, $\mathrm{n}(\%)$ & & $5(16.7)$ \\
\hline History of coronary stenting, $\mathrm{n}(\%)$ & & $10(30)$ \\
\hline Diabetes mellitus, $\mathrm{n}(\%)$ & $2(6.7)$ & $8(26.7)^{*}$ \\
\hline History of heart failure of NYHA functional class I-II, n (\%) & $14(46.7)$ & $21(70)$ \\
\hline History of atrial fibrillation, $\mathrm{n}(\%)$ & I (3.3) & $6(20)^{*}$ \\
\hline Albuminuria, n (\%) & $12(40)$ & $18(60)$ \\
\hline Baseline antihypertensive therapy: & $n=18(60 \%)$ & $\mathrm{n}=30(100 \%)^{* * *}$ \\
\hline ACEis, $n(\%)$ & $10(55.6)$ & $15(50)$ \\
\hline Beta-blockers, n (\%) & $12(66.7)$ & $29(96.7)^{* *}$ \\
\hline CCBs, n (\%) & $8(44.4)$ & $2(6.7)^{* *}$ \\
\hline Diuretics, n (\%) & $9(50)$ & $12(40)$ \\
\hline Monotherapy, n (\%) & $10(55.6)$ & $3(10)^{* *}$ \\
\hline Combination therapy, $\mathrm{n}(\%)$ & $8(44.4)$ & $27(90)^{* *}$ \\
\hline Statins, n (\%) & $19(63.3)$ & $30(100)^{* * * *}$ \\
\hline ASA, n (\%) & $14(46.7)$ & $30(100)^{* * * *}$ \\
\hline Nitrates on demands, $\mathrm{n}(\%)$ & - & $24(80)$ \\
\hline
\end{tabular}

Notes: Significance of differences between groups: $* P<0.05$, $* * P<0.02$, $* * * P<0.001$.

Abbreviations: ASA, acetylsalicylic acid; BMI, body mass index; CCB, calcium channel blocker; DBP, diastolic blood pressure; HR, heart rate; ACEi, angiotensin-converting enzyme inhibitor; IHD, ischemic heart disease; NYHA, New York Heart Association; SBP, systolic blood pressure. 

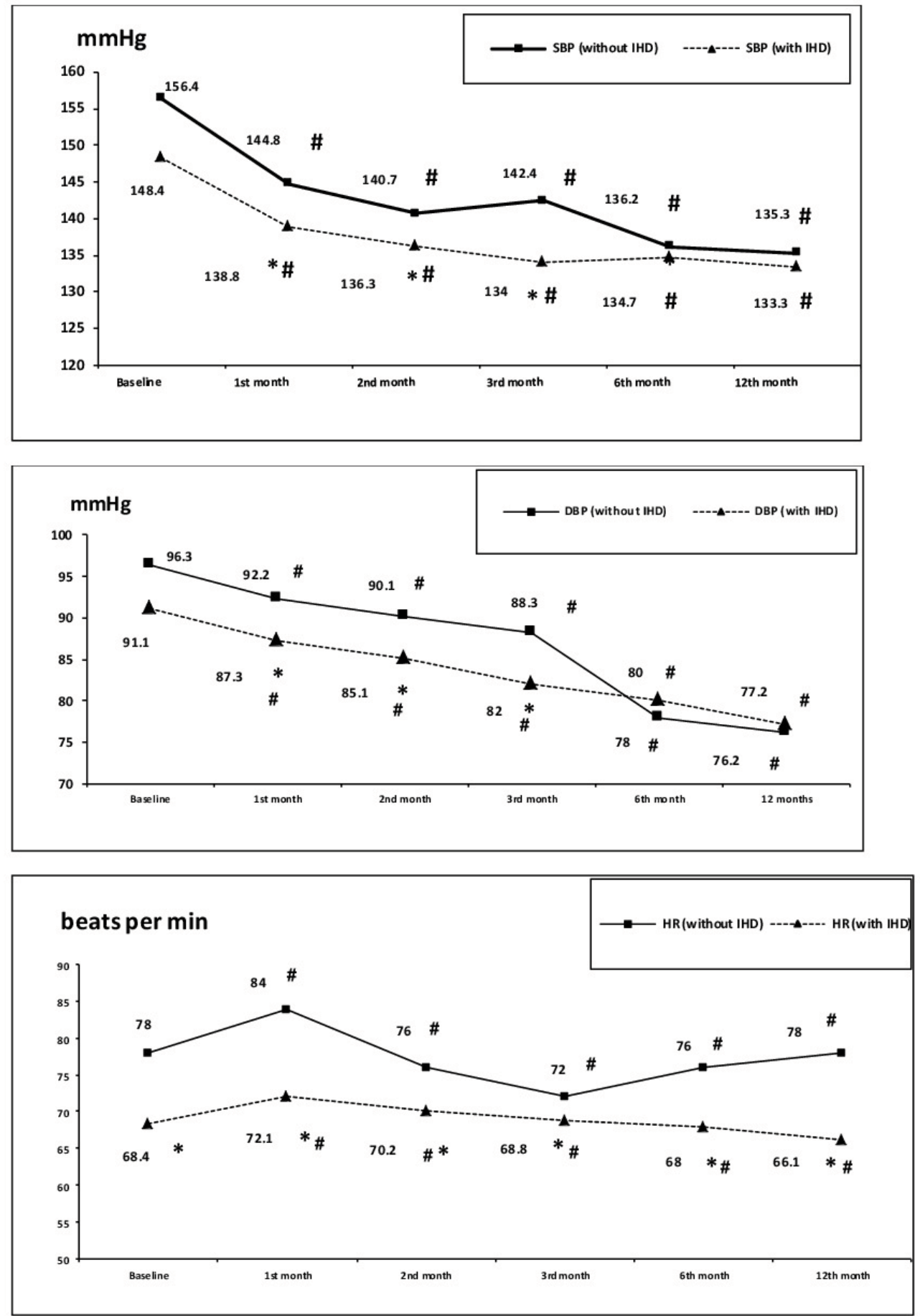

Figure I Dynamics of office SBP, DBP, and HR on therapy in groups: \#Significant in comparison with baseline in the same group. *Significant in comparison with group of patients without IHD at the same period.

Abbreviations: DBP, diastolic blood pressure; HR, heart rate; IHD, ischemic heart disease; SBP, systolic blood pressure.

ABPM data are presented in Table 3. Baseline groups did not have significant differences of BP levels, but patients with IHD had less 24-hour HR and higher daytime and nighttime SBP and DBP variabilities. In both groups, we noted significant lowering of 24-hour, daytime, and nighttime SBP/
DBP - by $22.3 \pm 0.1,19.6 \pm 0.4,26.1 \pm 0.2 / 8.2 \pm 0.2,8.4 \pm 0.1$, and $7.9 \pm 0.1 \mathrm{mmHg}$, respectively, in the group without IHD and by $20.7 \pm 0.08,16.4 \pm 0.2,25.1 \pm 0.1 / 12.6 \pm 0.1,14.1 \pm 0.09$, and $11.5 \pm 0.1 \mathrm{mmHg}$, respectively, in the group with IHD. However, the reduction $(\Delta)$ of 24-hour, daytime, and night- 
time SBP was more prominent in the patients without IHD and lowering of 24-hour, daytime, and nighttime DBP was more prominent in the IHD group (Figure 2). The target 24-hour BP level was achieved in 29 (98.7\%) patients in the first group and $28(93.3 \%)$ patients in the second group (not clinically significant; NS). At the end of trial, no significant differences in 24-hour, daytime, and nighttime SBP and DBP were noted between the groups.

Ambulatory HR did not change significantly in any group, but it was significantly less at baseline and at the end of treatment in the group with IHD.

Daytime and nighttime SBP variability, and daytime DBP variability decreased significantly in both groups, but nighttime DBP variability decreased only in the group with IHD.

At baseline, $50 \%$ and $53.3 \%(P=\mathrm{NS})$ of patients in the first and second groups, respectively, were "non-dipper." Under treat- ment we noted a decrease in the "non-dipper" rate till 23.3\% in the group without IHD. In this group, DI of SBP increased significantly from $10.6 \pm 0.8 \%$ to $17.8 \pm 1.9 \%(P<0.005)$.

At baseline, the proportion of patients with high morning surge ( $>55 \mathrm{mmHg}$ ) was more in the group with IHD compared with the group without IHD $(83.3 \%$ vs $60 \%$, respectively, $P<0.05)$. The mean values of morning surge decreased significantly in both groups; however, at the end of study, the proportion of patients with high morning surge remained higher in the group with IHD compared with the group without IHD.

The central SBP and Aix@75 in both groups are presented in Figure 3. At baseline, the groups were adjusted to central SBP. Under treatment, central SBP decreased significantly and at the same degree in both groups. The lowering of Aix@75 was significant in both groups but more prominent in the group without IHD.
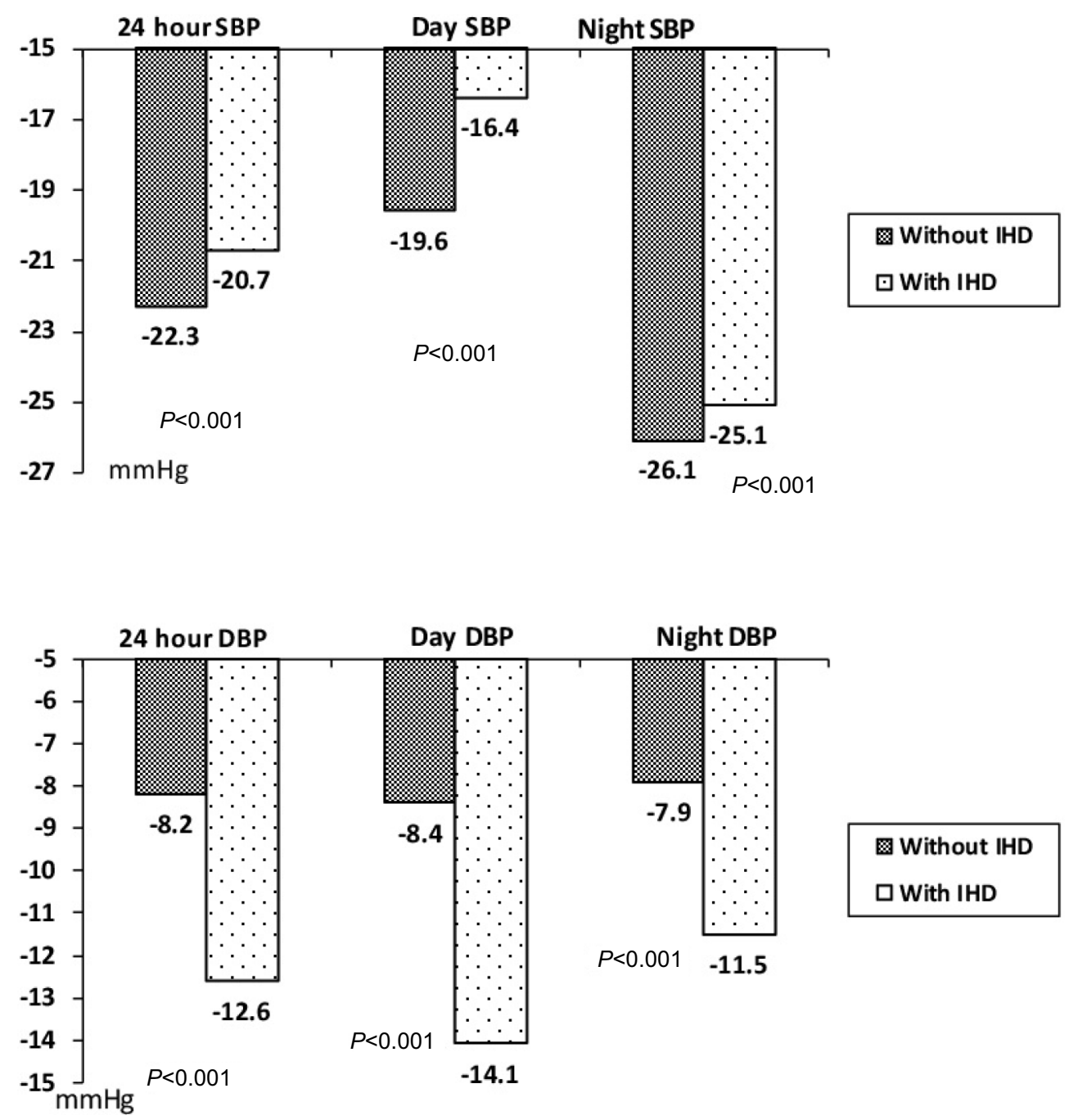

Figure 2 Lowering of 24-hour, daytime, and nighttime SBP and DBP in the treatment groups.

Abbreviations: DBP, diastolic blood pressure; IHD, ischemic heart disease; SBP, systolic blood pressure. 
Table 3 Dynamics of ABPM patterns in the patient groups

\begin{tabular}{|c|c|c|c|c|c|c|}
\hline \multirow[t]{2}{*}{ Patterns } & \multicolumn{3}{|c|}{ Without IHD $(n=30)$} & \multicolumn{3}{|c|}{ With IHD $(n=30)$} \\
\hline & Baseline & 12 months & $P$-value & Baseline & 12 months & $P$-value \\
\hline 24-hour SBP, mmHg & $140.2 \pm 1.9$ & $117.8 \pm 1.4$ & $<0.001$ & $139.8 \pm 2.0$ & $118.9 \pm 1.3$ & $<0.001$ \\
\hline 24-hour DBP, mmHg & $83.4 \pm 2.2$ & $75.2 \pm 1.1$ & $<0.001$ & $85.8 \pm 2.7$ & $73.2 \pm 1.2$ & $<0.001$ \\
\hline 24-hour HR, beats per minute & $74.2 \pm 2.9$ & $72.3 \pm 1.8$ & NS & $69.3 \pm 2.7$ & $66.1 \pm 2.8$ & NS \\
\hline DI for SBP, \% & $10.6 \pm 0.8$ & $17.8 \pm 1.9$ & $<0.005$ & $9.2 \pm 0.7$ & $10.9 \pm 0.9 * *$ & NS \\
\hline Daytime SBP, mmHg & $148.8 \pm 2.3$ & $129.2 \pm 1.4$ & $<0.001$ & $146.4 \pm 2.8$ & $129.8 \pm 1.1$ & $<0.001$ \\
\hline Daytime DBP, $\mathrm{mmHg}$ & $90.7 \pm 1.8$ & $82.3 \pm 1.1$ & $<0.001$ & $89.7 \pm 1.8$ & $75.6 \pm 1.3^{*}$ & $<0.001$ \\
\hline Daytime HR, beats per minute & $80.2 \pm 2.4$ & $79.2 \pm 1.8$ & NS & $73.2 \pm 2.4^{* * *}$ & $69.9 \pm 1.8^{*}$ & NS \\
\hline Variability of daytime SBP, $\mathrm{mmHg}$ & $17.4 \pm 0.1$ & $14.1 \pm 0.2$ & $<0.001$ & $18.8 \pm 0.1 *$ & $12.1 \pm 0.2^{*}$ & $<0.001$ \\
\hline Variability of daytime DBP, $\mathrm{mmHg}$ & $14.8 \pm 0.2$ & $13.7 \pm 0.3$ & $<0.005$ & $16.1 \pm 0.1 *$ & $13.2 \pm 0.2$ & $<0.001$ \\
\hline Nighttime SBP, mmHg & $132.2 \pm 1.8$ & $106.1 \pm 1.3$ & $<0.001$ & $133.2 \pm 2.1$ & $108.1 \pm 1.3$ & $<0.001$ \\
\hline Nighttime DBP, mmHg & $76.1 \pm 2.6$ & $68.3 \pm 1.0$ & $<0.01$ & $82.1 \pm 2.3$ & $70.7 \pm 1.0$ & $<0.001$ \\
\hline Nighttime HR, beats per minute & $68.3 \pm 3.5$ & $65.4 \pm 1.9$ & NS & $65.4 \pm 3.5$ & $62.4 \pm 1.9$ & NS \\
\hline Variability of nighttime SBP, $\mathrm{mmHg}$ & $15.2 \pm 0.2$ & $12.7 \pm 0.3$ & $<0.001$ & $16.7 \pm 0.3^{*}$ & $12.2 \pm 0.3$ & $<0.001$ \\
\hline Variability of DBP, $\mathrm{mmHg}$ & $10.1 \pm 0.1$ & $10.3 \pm 0.2$ & NS & $14.3 \pm 0.2^{*}$ & $11.3 \pm 0.2^{* *}$ & $<0.001$ \\
\hline Morning surge of SBP, $\mathrm{mmHg}$ & $68.9 \pm 5.6$ & $49.9 \pm 4.4$ & $<0.02$ & $66.4 \pm 4.3$ & $50.9 \pm 4.6$ & $<0.02$ \\
\hline Prevalence of patients with morning surge of SBP $>55 \mathrm{mmHg}, \mathrm{n}(\%)$ & $18(60)$ & $6(20)$ & $<0.005$ & $25(83.3)^{* * * *}$ & $14(46.7)^{* * * *}$ & $<0.005$ \\
\hline Prevalence of "non-dipper" patients, n (\%) & $15(50 \%)$ & $7(23.3)$ & $<0.05$ & $16(53.3 \%)$ & $12(40)$ & NS \\
\hline
\end{tabular}

Notes: Significance between groups at the same period of treatment: $* P<0.001, * * P<0.005, * * * P<0.05$.

Abbreviations: ABPM, ambulatory blood pressure monitoring; DBP, diastolic blood pressure; DI, daily index; HR, heart rate; IHD, ischemic heart disease; NS, not clinically significant; SBP, systolic blood pressure.
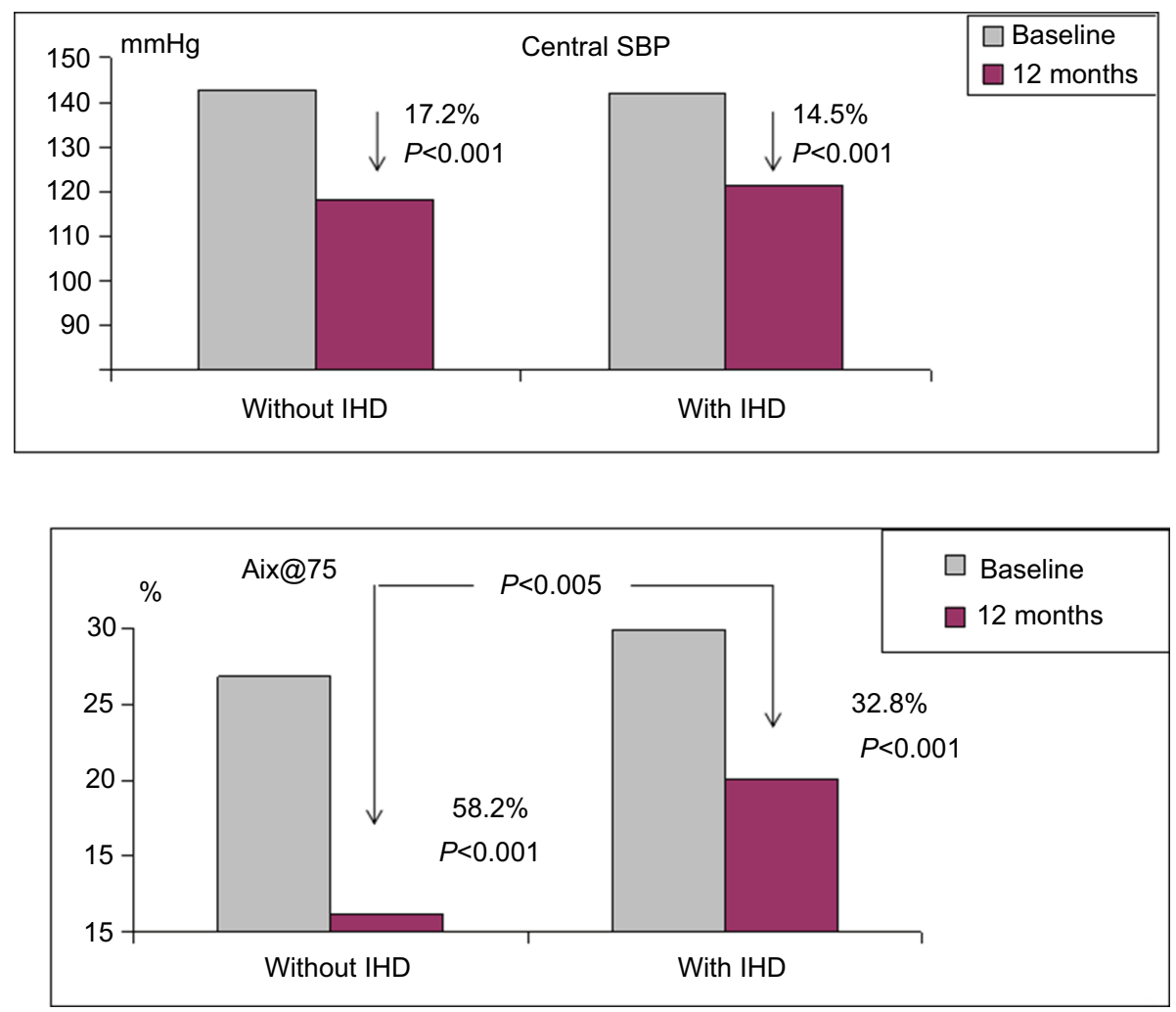

Figure 3 Dynamics of central SBP and Aix@75 in the treatment groups.

Abbreviations: Aix@75, augmentation index adjusted to heart rate 75; IHD, ischemic heart disease; SBP, systolic blood pressure. 
TOD patterns and their dynamics are presented in Table 4. At baseline, there were some differences between both groups. Patients with IHD had more prominent changes in carotid arteries, LVH, left ventricle diastolic function, and left atrium size. The level of GFR was somewhat lower in the patients with IHD than in those without IHD (65.2 \pm 10.1 vs $87.9 \pm 8.7 \mathrm{~mL} / \mathrm{min} / 1.73 \mathrm{~m}^{2}$, respectively), but not statistically significant.

During the treatment, we noted improvement in arterial stiffness, left ventricular diastolic function, albuminuria level, LVH, and left atrium size. The IMTmax decreased in both groups, but it was significant only in the patients with IHD. The mean IMT did not change significantly in either group.

Lowering of PWVe ( $\triangle \mathrm{PWVe})$ was significantly less in the group without IHD than the group with IHD $(-2.5 \pm 0.2$ to $-4.4 \pm 0.5 \mathrm{~m} / \mathrm{s}, P<0.005)$. In spite of absence of differences between the groups in LVMI, increase of E/A and decrease of E/ $\mathrm{E}^{\prime}$ (the left ventricular diastolic function improving) were more prominent in patients with IHD than those without IHD $(64.4 \%$ and $54.1 \%$ vs 39.8 and $23.2 \%$, respectively; $P<0.05$ for both).

No significant changes in GFR were noted in either group. However, the proportion of patients with albuminuria decreased significantly from $12(40 \%)$ to $5(16.7 \%)$ in the group without IHD and from $18(60 \%)$ to $10(33.3 \%)$ in the group with IHD. At baseline and at the end of study, the group with IHD had more number of patients with albuminuria.

\section{Biochemical changes}

At baseline, the groups did not have significant differences between them in terms of most biochemical patterns, except for patients with IHD having lower level of total cholesterol than those without IHD. It could be explained by the fact that all patients in the IHD group took statins.

During the treatment, no significant dynamics of biochemical patterns were noted in either group, except for a significant decrease in the levels of total cholesterol (from 6.9 \pm 0.6 to $4.7 \pm 0.8 \mathrm{mmol} / \mathrm{L}$ and from $5.4 \pm 0.4$ to $4.1 \pm 0.2 \mathrm{mmol} / \mathrm{L}$, respectively, in the first and second groups; $P<0.05$ for both groups) and triglyceride (from $2.6 \pm 0.3$ to $1.6 \pm 0.3 \mathrm{mmol} / \mathrm{L}$ and from $2.9 \pm 0.3$ to $1.7 \pm 0.3 \mathrm{mmol} / \mathrm{L}$, respectively, in the first and second groups; $P<0.05$ for both groups) due to statin therapy.

\section{Safety}

In total, 34 patients were included in the group without IHD and 31 in the group with IHD. One patient in the group without IHD and one patient in the group with IHD were excluded from the study because of cough. Three patients without IHD were lost to follow-up and were replaced by other matched patients. During the treatment, one patient in the first group and 2 patients in the second group developed peripheral edema, but they continued to participate in the study according to protocol. Thus, among the patients treated with FDC perindopril/amlodipine and who finished the study according to protocol, adverse reactions were noted in $2(6.5 \%)$ patients in the group without IHD and $3(10 \%)$ patients in the group with IHD $(P=\mathrm{NS})$. Among patients with IHD, we noted a decrease in angina rate from $2.5 \pm 0.4$ to $1.2 \pm 0.2$ per week $(P<0.01)$.

\section{Discussion}

At baseline, the two groups were adjusted by main clinicodemography patterns, including office, ambulatory, and

Table 4 Dynamics of TOD patterns in the treatment groups

\begin{tabular}{|c|c|c|c|c|c|c|}
\hline \multirow[t]{2}{*}{ Patterns } & \multicolumn{3}{|c|}{ Without IHD $(n=30)$} & \multicolumn{3}{|c|}{ With IHD $(n=30)$} \\
\hline & Baseline & 12 months & P2-3 & Baseline & 12 months & P5-6 \\
\hline I & 2 & 3 & 4 & 5 & 6 & 7 \\
\hline $\mathrm{PWVe}, \mathrm{m} / \mathrm{s}$ & $11.9 \pm 0.7$ & $9.4 \pm 0.8$ & 0.05 & $13.9 \pm 0.8$ & $9.5 \pm 0.7$ & 0.01 \\
\hline $\mathrm{PWVm}, \mathrm{m} / \mathrm{s}$ & $10.9 \pm 0.9$ & $10.4 \pm 0.8$ & NS & II. $I \pm 0.7$ & $10.3 \pm 0.9$ & NS \\
\hline Ankle-brachial index & $1.00 \pm 0.05$ & $I . I \pm 0.08$ & NS & $0.9 \pm 0.05$ & $1.0 \pm 0.08$ & NS \\
\hline IMTmax, mm & $1.1 \pm 0.03$ & $1.0 \pm 0.04$ & NS & $1.30 \pm 0.02 *$ & $1.2 \pm 0.03 * *$ & 0.05 \\
\hline Albuminuria, mg/day & $53.3 \pm 5.6$ & $15.8 \pm 3.2$ & 0.001 & $72.5 \pm 7.6$ & $14.8 \pm 3.1$ & 0.001 \\
\hline Calculated GFR, $\mathrm{ml} / \mathrm{min} / 1.73 \mathrm{~m}^{2}$ & $87.9 \pm 8.7$ & $83.6 \pm 9.1$ & NS & $65.2 \pm 10.1$ & $68.6 \pm 7.1$ & NS \\
\hline LVMI, $g / m^{2}$ & $108.8 \pm 5.5$ & $88.3 \pm 5.3$ & 0.02 & $125.9 \pm 5.5^{* * * *}$ & $108.3 \pm 6.3^{* * *}$ & 0.05 \\
\hline E/A & $0.93 \pm 0.06$ & $1.3 \pm 0.08$ & 0.001 & $0.73 \pm 0.05 * *$ & $1.2 \pm 0.08$ & 0.001 \\
\hline $\mathrm{E} / \mathrm{E}^{\prime}$ & $9.9 \pm 0.2$ & $7.6 \pm 0.5$ & 0.001 & $15.9 \pm 0.2^{*}$ & $7.3 \pm 0.4$ & 0.001 \\
\hline Cornel index, $\mathrm{mm} \cdot \mathrm{ms}$ & $2440.1 \pm 67.9$ & $1987.2 \pm 66.8$ & 0.001 & $2948.4 \pm 77.2 *$ & $2687.2 \pm 56.8^{*}$ & 0.01 \\
\hline Left atrium size, $\mathrm{mm}$ & $4 I . I \pm 0.2$ & $38.1 \pm 0.3$ & 0.001 & $42.5 \pm 0.5^{* *}$ & $4 I . I \pm 0.4 *$ & 0.05 \\
\hline
\end{tabular}

Notes: Significance of differences between groups. $* P<0.001$, $* * P<0.02$, $* * * P<0.05$.

Abbreviations: GFR, glomerular filtration rate; IHD, ischemic heart disease; IMTmax, maximal intima-media thickness; LVMI, left ventricular mass index; NS, not clinically significant; PWVe, aorta pulse wave velocity; PWVm, muscular pulse wave velocity. 
aorta BP levels. However, the patients with IHD had higher daytime and nighttime SBP variability and morning surge. In some studies, BP variability was associated with $\mathrm{TOD}^{21}$ and increased cardiovascular risk irrespective of the office BP level (Table 5). Miao and Su demonstrated that chronic high BP variability led to more prominent left ventricular and artery hypertrophy in sino-aorta denervated rats. ${ }^{22}$ This was explained by increased collagen, decreased elastin, smooth muscle stimulation, cardiomyocyte necrosis, mononuclear infiltration, and narrowing of coronary arteries. Exacerbation of cardiomyocyte hypertrophy was provided partly by diminished aorta elasticity. ${ }^{23-25}$ In addition, higher BP variability was associated with higher glomerular damage. ${ }^{23}$

The studies presented in Table 5 demonstrated the correlation between BP variability and TOD in patients with arterial hypertension. Parati et al found relations between 24-hour BP variability and prevalence and degree of TOD irrespective of the level of 24-hour BP. ${ }^{26}$ In another study, short-time BP variability was measured intra-arterially. After seven years of follow-up, associations between cardiovascular complications, LVH, and BP variability were noted. ${ }^{27}$ In the ELSA trial, IMT was shown to correlate significantly with 24-hour BP variability. ${ }^{28}$ In the PAMELA study, Sega et al demonstrated the correlation between BP variability and LVH in hypertensive patients without therapy. ${ }^{29}$ In a three-year follow-up study, BP variability was a strong and an independent predictor of early atherosclerosis of carotid arteries in the general population. ${ }^{30}$ Among patients with chronic kidney diseases, the total and cardiovascular deaths, respectively, were 2.82 and 4.9 times higher if BP variability was high. ${ }^{31}$ In other observations, high BP variability was associated with arterial stiffness, ${ }^{32,33}$ atherosclerotic plaques, and increased peripheral resistance. ${ }^{34}$ Correlations of BP variability with coronary restenosis after angioplasty ${ }^{35}$ and increased coronary damage risk in diabetes ${ }^{36}$ could evidence that high BP variability may play a role in the pathogenesis of IHD. Additionally, variability was associated with stroke and myocardial infarction risk. ${ }^{41,42}$ Hence, finding an optimal antihypertensive therapy that reduces not only the level of BP but also its variability is important. Some studies evidenced that diuretics and CCBs, especially amlodipine, are the most effective antihypertensive drugs in decreasing BP variability. ${ }^{43-45}$ The FDC amlodipine/perindopril significantly lowered the office BP variability in the ASCOT trial, which was associated with improvement in prognosis. ${ }^{46}$ Our study confirmed the efficacy of FDC perindopril/amlodipine in decreasing baseline high daytime and nighttime variability in hypertensive patients with and without IHD.

According to ABPM data, 24-hour, daytime, and nighttime SBP lowered more prominently in the patients without IHD, but respective DBP lowered in the patients with IHD. This could be due to the higher baseline, 24-hour, daytime, and nighttime SBP in the group without IHD than in the group with IHD. On the contrary, baseline, 24-hour, daytime, and nighttime DBP were higher in the group with IHD than in the group without IHD. It is well known that the higher

Table 5 Studies evaluating the effects of high BP variability on TOD and cardiovascular events

\begin{tabular}{|c|c|c|c|}
\hline Study & Population & Variability & Influence \\
\hline Parati et $\mathrm{al}^{26}$ & $\begin{array}{l}\text { Hospitalized patients with essential } \\
\text { arterial hypertension }\end{array}$ & 24-hour variability & Increased TOD rate \\
\hline Frattola et $\mathrm{al}^{27}$ & Patients with arterial hypertension & Daytime SBP variability & More prominent TOD \\
\hline Mancia et $\mathrm{al}^{28}$ & Patients with arterial hypertension & 24-hour variability & Increased IMT \\
\hline Sega et $\mathrm{al}^{29}$ & General population & Total variability & More LVMI \\
\hline Sander et $\mathrm{al}^{30}$ & General population & Daytime variability & IMT progression \\
\hline McMullan et $\mathrm{al}^{31}$ & Patients with chronic kidney disease & SBP variability & Increased total and cardiovascular death \\
\hline Kawai et $\mathrm{al}^{34}$ & Patients with arterial hypertension & $\begin{array}{l}\text { Daytime SBP variability } \\
\text { Nighttime SBP variability }\end{array}$ & $\begin{array}{l}\text { Increased renal artery resistance } \\
\text { Increased IMT }\end{array}$ \\
\hline Cay et $\mathrm{al}^{35}$ & Normotensive patients & $\begin{array}{l}\text { 24-hour SBP and DBP } \\
\text { variability }\end{array}$ & $\begin{array}{l}\text { Increased restenosis risk after } \\
\text { percutaneous coronary interventions }\end{array}$ \\
\hline Ozawa et $\mathrm{al}^{36}$ & Patients with type 2 diabetes & $\begin{array}{l}\text { Nighttime SBP and DBP } \\
\text { variability }\end{array}$ & Increased rate of cardiovascular events \\
\hline Sakakura et $\mathrm{al}^{37}$ & Elderly patients & Daytime SBP variability & Cognitive dysfunction, poor quality of life \\
\hline Iwata et $\mathrm{al}^{38}$ & Patients with arterial hypertension & Nighttime SBP variability & More atherosclerotic plaques \\
\hline Schillaci et al $^{39}$ & Patients with arterial hypertension & 24-hour variability & Increased arterial stiffness \\
\hline Schutte et $\mathrm{al}^{40}$ & Normotensive Afro-Americans & 24-hour variability & LVH \\
\hline
\end{tabular}

Abbreviations: BP, blood pressure; DBP, diastolic blood pressure; IMT, intima-media thickness; LVH, left ventricular hypertrophy; LVMI, left ventricular mass index; SBP, systolic blood pressure; TOD, target organ damage. 
the baseline BP is, the more degree of its lowering could be expected.

In our study, patients with and without IHD did not differ by baseline level of central SBP and Aix@75, but therapy led to equal decrease in central SBP and much more prominent lowering of Aix@75 in the group without IHD than in the group with IHD. This could be explained by lower HR in patients with IHD due to the treatment with beta-blockers at all periods of the study. In the ASCOT trial, aorta SBP was associated with on-treatment $\mathrm{HR}$ - the lesser the HR was, the higher the central SBP left. This is why beta-blockers are less effective in decreasing central SBP. According to the ASCOT trial data, lowering of HR by 10 beats per minute was associated with increase in central SBP by $3 \mathrm{mmHg}$ and Aix by $2.5 \% .{ }^{47}$ There are at least three reasons for this. First, diminishing of HR leads to systole prolongation and reflected pulse wave returns in systole, adds to direct pulse wave, and increases central SBP. Second, beta-blockers could be the cause of vasospasm and displace proximally the point of pulse wave reflection, which helps reflected pulse wave to return earlier. In addition, higher vascular resistance increases pulse wave amplitude. Third, BP is cardiac output $\times$ peripheral resistance, where cardiac output $=$ stroke volume $\times$ HR. When HR decreases with treatment, mean BP is supported by increase in stroke volume. In patients of older age and those who suffered from hypertension or atherosclerosis, the reduction of HR leads to increase in stroke volume, which is not compensated by stretching of capacitive vessels (due to age and structure changes in the walls under diseases). Thus, aorta SBP and pulse BP increased. Any HR-lowering drug would be less effective in reducing aorta BP than others. However, there are some exclusions. Vasodilating beta-blockers could be more beneficial than others. ${ }^{48,49}$ In addition, the study of Matsui et al demonstrated that the combination of olmesartan/ azelnidipine decreased central SBP more significantly than the combination olmesartan/hydrochlorothiazide, while also reducing HR more prominently. ${ }^{50}$ The authors explained it by more positive influence of olmesartan/azelnidipine on peripheral resistance and PWV. That means there are some additional pleotropic effects of antihypertensive drugs (influence on capacitive artery structure, endothelium function, vasodilating) that could neutralize the act of HR lowering.

As shown in our study, patients with arterial hypertension and IHD had more damaged carotid arteries, LVH, diastolic dysfunction, and enlarged left atrium. They also had less GFR. These differences confirmed the results of another study in which hypertensive patients with IHD had more LVH and
IMT in comparison with patients without IHD. ${ }^{51}$ However, that study did not evaluate the on-treatment changes in TOD as was done in our study.

We found the treatment with FDC perindopril/amlodipine improved arterial stiffness and left ventricular diastolic function, and decreased albuminuria level, $\mathrm{LVH}$, and left atrium size. IMTmax decreased significantly only in the group with IHD. PWVe lowering ( $\triangle \mathrm{PWVe}$ ) was more prominent in patients with IHD. These more advanced artery changes in the patients with IHD could be explained partly by the fact that all patients in this group took statin therapy, whereas only $63 \%$ of patients in the other group took statin therapy. Evidence from some other studies shows that statins have positive effects on atherosclerotic regression and enhance the effect of FDC on arteries. ${ }^{52-55}$ In the ASCOT trial, significant differences in the rates of myocardial infarction and stroke were observed between patients on atorvastatin and amlodipine (+ perindopril) and those on amlodipine (+ perindopril) only. ${ }^{55}$ The authors explained it by the synergetic action of amlodipine (restoring of vascular tonus, improvement of endothelial function, decrease in smooth myocyte migration, etc), perindopril (endothelial oxidative stress reduction, improvement of endothelial function, reduction of thrombocyte aggregation, vasodilation, reduction of atherosclerotic biomarkers [D-dimer, cytokines, TNF- $\alpha$ ], and apoptosis), and atorvastatin. ${ }^{56,57}$ It was considered that IMT regression on statin therapy was connected with reduction of intima thickness, while that on vasodilating therapy was connected with reduction of media thickness.

There is not much evidence showing significantly effective reduction of IMT on antihypertensive therapy. In the CAMELOT study, more strict BP control $(<120 / 80 \mathrm{~mm}$ $\mathrm{Hg}$ ) was associated with reduction of atherosclerotic plaque volume. ${ }^{58}$ Ariff et al demonstrated that both atenolol and candesartan therapy led to decrease in IMT, but candesartan therapy was more effective. ${ }^{59}$ In the LIFE study, a more significant reduction of IMT was noted with losartan therapy than atenolol. ${ }^{60}$ Some other trails demonstrated the deceleration of IMT progression on therapy only. In the ELSA trial, IMT increased in both groups of treatment, but to a lesser extent in the lacidipine group than in the atenolol group. ${ }^{61}$ However, this positive effect of lacidipine was not associated with prognosis - both groups had no differences in complication rates. Klause et al showed equal effects of olmesartan and atenolol on IMT, but the total atherosclerotic plaque volume was less in the angiotensin receptor blocker group. ${ }^{62}$ During the same time period, there is more evidence of atherosclerotic regression with statin therapy. These atherosclerotic 
changes were better demonstrated during MRI tomography than ultrasound investigations. ${ }^{63}$

The LVMI reductions ( $\triangle \mathrm{LVMI})$ did not differ in our groups, but $\Delta \mathrm{E} / \mathrm{A}$ and $\Delta \mathrm{E} / \mathrm{E}^{\prime}$ (improvement of left ventricular diastolic function) were much higher in the group with IHD. It could be explained partly by more positive changes of arterial stiffness in the IHD group. Some studies established the correlation between PWV and left ventricular diastolic function even before LVH appearance, which may suggest the pathogenic role of arterial stiffness in diastolic dysfunction. ${ }^{64,65}$ The other explanation of more prominent improvement of diastolic function could be the baseline worse patterns in patients with IHD than in those without IHD. It is known that higher baseline patterns have more chance for better changes on treatment.

Results of our study concerning $\mathrm{E} / \mathrm{E}^{\prime}$ changes in the groups are somewhat different from the subanalysis results of the ASCOT trial. ${ }^{66}$ Those results demonstrated that the decrease in LVMIs was equal ( $P=\mathrm{NS}$ between groups) in both therapy groups (amlodipine + perindopril and atenolol + thiazide), but $\mathrm{E} / \mathrm{E}^{\prime}$ did not change significantly in the amlodipine group and increased significantly in the atenolol group. In our study, E/E' decreased significantly in both groups. It could be explained by the study design. We followed patients from baseline and at all periods of treatment, but in the ASCOT substudy evaluation of E/E' was started on average 1.5 years after patients' enrollment in the trial (Phase 1) and 2 years after the first measurement (Phase 2). Thus, it was impossible to exactly know whether E/E' changed or not with the treatment. We could only know that there were no changes on amlodipine (+ perindopril) and was worsening on atenolol (+ thiazide) during 3.5 years of follow-up.

In conclusion, therapy based on FDC perindopril/amlodipine was effective and safe in providing extensive BP control (office, ambulatory, and central BP) irrespective of the presence of IHD. Thus, this FDC could be included in the standards of treatment of arterial hypertension in patients with and without IHD. Effective BP control therapy led to significant regression of TOD, but with different degrees in different groups - more prominent positive changes in diastolic function and arterial stiffness were noted in the group with IHD. Thus, it could be considered in the management of patients with and without IHD.

\section{Study limitations}

Our study had some limitations. First, it was conducted in only one center (where PWV device is present) and did not include a large number of patients. However, statistical methods were validated for this number of patients. Second, our study was not blinded, but specialists provided the instrumental measurements (not treatment) only and were not interested in positive results. Third, we did not have the comparative group for other therapy, which could have effect on TOD in the same way as in good BP control. However, our study aimed to evaluate the differences in TOD regression in patients with and without IHD, but not to confirm the effectiveness of FDC. For reaching this goal we needed to use the same therapy for both patients with and without IHD. Fourth, the patients took statins during the 12 months, which could influence arterial stiffness and enhance the antihypertensive treatment effects, including BP lowering.

\section{Acknowledgments}

This study was supported by grant of Servier company (France). The authors did not obtain any financial benefits for conducting this study.

\section{Disclosure}

GD Radchenko and YM Sirenko had honorariums from Servier for educational lectures. The authors report no other conflicts of interest in this work.

\section{References}

1. Moser M, Hebert PR. Prevention of disease progression, left ventricular hypertrophy and congestive heart failure in hypertension treatment trials. J Am Coll Cardiol. 1996;27(5):1214-1218.

2. Palmieri V, Dahlöf B, Dequattro V, et al. Reliability of echocardiographic assessment of left ventricular structure and function: the PRESERVE study. Prospective Randomized Study Evaluating Regression of Ventricular Enlargement. J Am Coll Cardiol. 1999;34(5):1625-1632.

3. Mancia G, Carugo S, Grassi G, et al. Prevalence of Left Ventricular Hypertrophy in Hypertensive Patients Without and With Blood Pressure Control: Data From the PAMELA Population. Hypertension. 2002;39(3):744-749.

4. Epstein M, Tobe S. What is the optimal strategy to intensify blood pressure control and prevent progression of renal failure? Curr Hypertens Rep. 2001;3(5):422-428.

5. Klag MJ, Whelton PK, Randall BL, et al. Blood pressure and end-stage renal disease in men. $N$ Engl J Med. 1996;334(1):13-18.

6. Smulyan H, Lieber A, Safar ME. Hypertension, Diabetes Type II, and Their Association: Role of Arterial Stiffness. Am J Hypertens. 2016;29(1):5-13.

7. Devereux RB, Wachtell K, Gerdts E, et al. Prognostic significance of left ventricular mass change during treatment of hypertension. JAMA. 2004;292(19):2350-2356.

8. Ibsen $\mathrm{H}$, Olsen $\mathrm{MH}$, Wachtell $\mathrm{K}$, et al. Reduction in albuminuria translates to reduction in cardiovascular events in hypertensive patients: losartan intervention for endpoint reduction in hypertension study. Hypertension. 2005;45(2):198-202.

9. Patel A, ADVANCE Collaborative Group, MacMahon S, et al. Effects of a fixed combination of perindopril and indapamide on macrovascular and microvascular outcomes in patients with type 2 diabetes mellitus (the ADVANCE trial): a randomised controlled trial. Lancet. 2007;370(9590):829-840.

10. Deloach SS, Townsend RR. Vascular stiffness: its measurement and significance for epidemiologic and outcome studies. Clin J Am Soc Nephrol. 2008;3(1):184-192. 
11. RitzE, MenneJ, HallerH. Prevalence of microalbuminuria in type 2 diabetes: lessons learned from the ROADMAP study. Nephrol Dial Transplant. 2012;27(Suppl 4):28-30.

12. Mancia G, Fagard R, Narkiewicz K, et al. Task Force Members. 2013 $\mathrm{ESH} / \mathrm{ESC}$ Guidelines for the management of arterial hypertension: the Task Force for the management of arterial hypertension of the European Society of Hypertension (ESH) and of the European Society of Cardiology (ESC). J Hypertension. 2013;31(7):1281-1357.

13. Yusuf S, Hawken S, Ounpuu S, et al. Effect of potentially modifiable risk factors associated with myocardial infarction in 52 countries (the INTERHEART study): case-control study. Lancet. 2004;364(9438): 937-952.

14. Prospective Studies Collaboration, Whitlock G, Lewington S, et al. Body-mass index and cause-specific mortality in 900000 adults: collaborative analyses of 57 prospective studies. Lancet. 2009;373(9669):1083-1096.

15. Guidelines of Ukrainian Association of Cardiologist. Dyslipidemia: diagnosis, prevention and treatment. Kyiv. 2011;49.

16. Kario K. Morning surge in blood pressure and cardiovascular risk: evidence and perspectives. Hypertension. 2010;56(5):765-773.

17. Levey A, Stevens L, Schmid C, et al. CKD-EPI (Chronic Kidney Disease Epidemiology Collaboration). A new equation to estimate glomerular filtration rate. Ann Intern Med. 2009;150(9):604-612.

18. Stein JH, Korcarz CE, Hurst RT, et al. Use of carotid ultrasound to identify subclinical vascular disease and evaluate cardiovascular disease risk: a consensus statement from the American Society of Echocardiography Carotid Intima-Media Thickness Task Force. Endorsed by the Society for Vascular Medicine. J Am Soc Echocardiogr. 2008;21(2):93-111.

19. Foppa M, Duncan BB, Rohde LE. Echocardiography-based left ventricular mass estimation. How should we define hypertrophy? Cardiovasc Ultrasound. 2005;3:17.

20. Lenter C. Geigy Scientific Tables. Basel: CIBA-GEIGY Corporation; 1990:278.

21. Parati G, Lantelme P. Blood pressure variability, target organ damage and cardiovascular events. J Hypertens. 2002;20(9):1725-1729.

22. Miao CY, Su DF, . The importance of blood pressure variability in rat aortic and left ventricular hypertrophy produced by sinoaortic denervation. J Hypertens. 2002;20(9):1865-1872.

23. Miao CY, Xie HH, Zhan LS, Su DF. Blood pressure variability is more important than blood pressure level in determination of end-organ damage in rats. J Hypertens. 2006;24(6):1125-1135.

24. Flues K, Moraes-Silva IC, Mostarda C, et al. Cardiac and pulmonary arterial remodeling after sinoaortic denervation in normotensive rats. Autonomic Neuroscience. 2012;166(1-2):47-53.

25. Su DF, Miao CY. Blood pressure variability and organ damage. Clin Exp Pharmacol Physiol. 2001;28(9):709-715.

26. Parati G, Pomidossi G, Albini F, Malaspina D, Mancia G. Relationship of 24-hour blood pressure mean and variability to severity of targetorgan damage in hypertension. J Hypertens. 1987;5(1):93-98.

27. Frattola A, Parati G, Cuspidi C, Albini F, Mancia G. Prognostic value of 24-hour blood pressure variability. J Hypertens. 1993;11(10):1133-1137.

28. Mancia G, Parati G, Hennig M, et al. Relation between blood pressure variability and carotid artery damage in hypertension: baseline data from the European Lacidipine Study on Atherosclerosis (ELSA). $J$ Hypertens. 2001;19(11):1981-1989.

29. Sega R, Corrao G, Bombelli M, Al Bmet, et al. Blood pressure variability and organ damage in a general population: results from the PAMELA study. Hypertension. 2002;39(2):710-714.

30. Sander D, Kukla C, Klingelhöfer J, Winbeck K, Conrad B. Relationship between circadian blood pressure patterns and progression of early carotid atherosclerosis: A 3-year follow-up study. Circulation. 2000;102(13):1536-1541.

31. Mcmullan CJ, Bakris GL, Phillips RA, Forman JP. Association of BP variability with mortality among African Americans with CKD. Clin J Am Soc Nephrol. 2013;8(5):731-738.
32. Fukui M, Ushigome E, Tanaka M, et al. Home blood pressure variability on one occasion is a novel factor associated with arterial stiffness in patients with type 2 diabetes. Hypertens Res. 2013;36(3):219-225.

33. García-García Á, García-Ortiz L, Recio-Rodríguez JI, et al. Relationship of 24-h blood pressure variability with vascular structure and function in hypertensive patients. Blood Press Monit. 2013;18(2):101-106.

34. Kawai T, Ohishi M, Kamide K, et al. Differences between daytime and nighttime blood pressure variability regarding systemic atherosclerotic change and renal function. Hypertens Res. 2013;36(3):232-239.

35. Cay S, Cagirci G, Demir AD, et al. Ambulatory blood pressure variability is associated with restenosis after percutaneous coronary intervention in normotensive patients. Atherosclerosis. 2011;219(2):951-957.

36. Ozawa M, Tamura K, Okano Y, et al. Identification of an increased short-term blood pressure variability on ambulatory blood pressure monitoring as a coronary risk factor in diabetic hypertensives. Clin Exp Hypertens. 2009;31(3):259-270.

37. Sakakura K, Ishikawa J, Okuno M, Shimada K, Kario K. Exaggerated ambulatory blood pressure variability is associated with cognitive dysfunction in the very elderly and quality of life in the younger elderly. Am J Hypertens. 2007;20(7):720-727.

38. Iwata S, Jin Z, Schwartz JE, et al. Relationship between ambulatory blood pressure and aortic arch atherosclerosis. Atherosclerosis. 2012;221(2): $427-431$.

39. Schillaci G, Bilo G, Pucci G, et al. Relationship between short-term blood pressure variability and large-artery stiffness in human hypertension: findings from 2 large databases. Hypertension. 2012;60(2):369-377.

40. Schutte AE, Schutte R, Huisman HW, et al. Blood pressure variability is significantly associated with ECG left ventricular mass in normotensive Africans: the SABPA Study. Hypertens Res. 2011;34(10):1127-1134.

41. Rothwell PM, Howard SC, Dolan E, et al. Prognostic significance of visit-to-visit variability, maximum systolic blood pressure, and episodic hypertension. Lancet. 2010;375(9718):895-905.

42. Cuffe RL, Rothwell PM. Medium-term variability in systolic blood pressure is an independent predictor of stroke. Cerebrovasc Dis. 2005;19(Suppl 2):5112.

43. Rothwell PM. Limitations of the usual blood-pressure hypothesis and importance of variability, instability, and episodic hypertension. Lancet. 2010;375(9718):938-948.

44. Webb AJ, Fischer U, Mehta Z, Rothwell PM. Effects of antihypertensive-drug class on interindividual variation in blood pressure and risk of stroke: a systematic review and meta-analysis. Lancet. 2010;375(9718):906-915.

45. Zhang Y, Agnoletti D, Safar ME, Blacher J. Effect of antihypertensive agents on blood pressure variability: the Natrilix SR versus candesartan and amlodipine in the reduction of systolic blood pressure in hypertensive patients (X-CELLENT) study. Hypertension. 2011;58(2):155-160.

46. Rothwell PM, Howard SC, Dolan E, et al. Effects of beta blockers and calcium-channel blockers on within-individual variability in blood pressure and risk of stroke. Lancet Neurol. 2010;9(5):469-480.

47. Williams B, Lacy P. for the CAFE and the ASCOT (Anglo-Scandinavian Cardiac Outcomes Trial) Investigators Impact of Heart Rate on Central Aortic Pressures and Hemodynamics Analysis From the CAFE (Conduit ArteryFunction Evaluation) Study: CAFE-Heart Rate. J Am CollCardiol. 2009;54:705-713.

48. Boutouyrie P, Tropeano AI, Asmar R, et al. Aortic stiffness is an independent predictor of primary coronary events in hypertensive patients: a longitudinal study. Hypertension. 2002;39(1):10-15.

49. Boutouyrie P, Achouba A, Trunet P, Laurent S, EXPLOR Trialist Group. Amlodipine-valsartan combination decreases central systolic blood pressure more effectively than the amlodipine-atenolol combination: the EXPLOR study. Hypertension. 2010;55(6):1314-1322.

50. Matsui Y, Eguchi K, O’Rourke MF, O’Rourke M, et al. Differential effects between a calcium channel blocker and a diuretic when used in combination with angiotensin II receptor blocker on central aortic pressure in hypertensive patients. Hypertension. 2009;54(4):716-723. 
51. Sheveleva O. Target organ damage in patients with arterial hypertension and ischemic heart disease, who live in Priobye. Thesis of Candidate of Medical Science. Available from: http://medical-diss.com/medicina/ porazhenie-organov-misheney-u-bolnyh-arterialnoy-gipertoniey-vsochetanii-s-ibs-prozhivayuschih-v-srednem-priobie.

52. Kamberi LS, Bedri Bakalli A, Muhamet Budima N, Budima NM, et al. Pleiotropic and Lipid-lowering Effects of Statins in Hypertension. Mater Sociomed. 2012;24(2):84-86.

53. Larosa JC, Grundy SM, Waters DD, et al. Intensive lipid lowering with atorvastatin in patients with stable coronary disease. $N$ Engl J Med. 2005;352(14):1425-1435.

54. Nissen SE, Tuzcu EM, Schoenhagen P, et al. Effect of intensive compared with moderate lipid-lowering therapy on progression of coronary atherosclerosis: a randomized controlled trial. JAMA. 2004;291(9):1071-1080.

55. Sever P, Dahlöf B, Poulter N, et al. Potential synergy between lipidlowering and blood-pressure-lowering in the Anglo-Scandinavian Cardiac Outcomes Trial. Eur Heart J. 2006;27(24):2982-2988.

56. Mason RP, Walter MF, Day CA, Jacob RF. Intermolecular differences of 3-hydroxy-3-methylglutaryl coenzyme a reductase inhibitors contribute to distinct pharmacologic and pleiotropic actions. Am J Cardiol. 2005;96(5A):11-23.

57. Munro E, Patel M, Chan P, et al. Inhibition of human vascular smooth muscle cell proliferation by lovastatin: the role of isoprenoid intermediates of cholesterol synthesis. Eur J Clin Invest. 1994;24(11):766-772.

58. Sipahi I, Tuzcu EM, Schoenhagen P, et al. Effects of normal, prehypertensive, and hypertensive blood pressure levels on progression of coronary atherosclerosis. J Am Coll Cardiol. 2006;48(4):833-838.
59. Ariff B, Zambanini A, Vamadeva S, et al. Candesartan- and AtenololBased Treatments Induce Different Patterns of Carotid Artery and Left Ventricular Remodeling in Hypertension. Stroke. 2006;37(9): 2381-2384.

60. Olsen MH, Wachtell K, Neland K, et al. Losartan but not atenolol reduce carotid artery hypertrophy in essential hypertension. A LIFE substudy. Blood Press. 2005;14(3):177-183.

61. AZ, MGB, MH, et al. Calcium Antagonist Lacidipine Slows Down Progression of Asymptomatic Carotid Atherosclerosis Principal Results of the European Lacidipine Study on Atherosclerosis (ELSA), a Randomized, Double-Blind, Long-Term Trial. Circulation. 2002;106: 2422-2427.

62. Klause O, StumpeK., EA-R, TZ, et al. Carotid intima-media thickness and plaque volume changes following 2-year angiotensin II-receptor blockade. The Multicentre Olmesartan atherosclerosis Regression Evaluation (MORE) study. Ther Adv Cardiovasc Dis. 2007;1(2):97-106.

63. Migrino RQ, Bowers M, Harmann L, Prost R, Ladisa JF. Carotid plaque regression following 6-month statin therapy assessed by $3 \mathrm{~T}$ cardiovascular magnetic resonance: comparison with ultrasound intima media thickness. J Cardiovasc Magn Reson. 2011;13(1):37.

64. Mottram PM, et al. Relation of arterial stiffness to diastolic dysfunction in hypertensive heart disease. Heart. 2005;91(12):1551-1556.

65. Daemen J. Diastolic dysfunction and arterial stiffness: the chicken or the egg. Neth Heart J. 2013;21(5):219-221.

66. Barron AJ, Hughes AD, Sharp A, et al. Long-Term Antihypertensive Treatment Fails to Improve E/E' Despite Regression of Left Ventricular Mass: An Anglo-Scandinavian Cardiac Outcomes Trial Substudy. Hypertension. 2014;63(2):252-258.
Vascular Health and Risk Management

\section{Publish your work in this journal}

Vascular Health and Risk Management is an international, peerreviewed journal of therapeutics and risk management, focusing on concise rapid reporting of clinical studies on the processes involved in the maintenance of vascular health; the monitoring, prevention and treatment of vascular disease and its sequelae; and the involvement of

\section{Dovepress}

metabolic disorders, particularly diabetes. This journal is indexed on PubMed Central and MedLine. The manuscript management system is completely online and includes a very quick and fair peer-review system, which is all easy to use. Visit http://www.dovepress.com/ testimonials.php to read real quotes from published authors. 